\title{
VIOLÊNCIA NA ESCOLA PÚBLICA: O QUE APONTAM TESES E DISSERTAÇÕES (2012-2019)?
}

\author{
VIOLENCIA EN LAS ESCUELAS PÚBLICAS: ¿QUÉ PUNTO DE TESIS Y \\ DISERTACIONES (2012-2019)?
}

\section{VIOLENCE IN PUBLIC SCHOOL: WHAT DO THESES AND DISSERTATIONS (2012- 2019) POINT OUT?}

\author{
Silésia Maria Sales PASSOS ${ }^{1}$ \\ Jean Mac Cole Tavares SANTOS ${ }^{2}$ \\ Emerson Augusto de MEDEIROS ${ }^{3}$
}

RESUMO: O artigo apresenta um levantamento bibliográfico acerca do tema "violência na escola pública". Refere-se a um estudo que se sustenta na análise de 16 dissertações e teses depositadas na Biblioteca Digital de Teses e Dissertações (BDTD). Utilizou-se como marco temporal o período de 2012 a 2019, creditando a produção acadêmica mais atual sobre o tema. No desenvolvimento da análise, considerou-se, principalmente, os objetivos dos estudos, algumas compreensões acerca da temática textualizadas nas pesquisas e as metodologias utilizadas. Concluiu-se que o tema "violência na escola pública" é complexo. Sua compreensão textualizada nas produções acadêmicas necessita estar associada às questões de cunho social mais amplo. No entanto, identificou-se que a escola pública tem condições de minimizar os diferentes tipos de violência que se sucedem em seu interior. Para isso, é essencial o trabalho coletivo e dialógico produzido em seu cotidiano.

PALAVRAS-CHAVE: Violência. Escola pública. Violência escolar.

RESUMEN: El artículo presenta un relevamiento bibliográfico sobre el tema "violencia en las escuelas públicas". Se refiere a un estudio que se basa en el análisis de 16 disertaciones y tesis depositadas en la Biblioteca Digital de Tesis y Disertaciones (BDTD). Se utilizó como marco temporal el periodo de 2012 a 2019, acreditando la producción académica más actual sobre el tema. En el desarrollo del análisis se consideró, principalmente, los objetivos de los estudios, algunas comprensiones sobre el tema textualizado en las investigaciones y las metodologías utilizadas. Se concluyó que el tema "violencia en las escuelas públicas" es complejo. Su comprensión textual en las producciones académicas debe asociarse con problemas sociales más amplios. Sin embargo, se identificó que las escuelas públicas son capaces de minimizar los diferentes tipos de violencia que ocurren dentro de ellas. Para ello, el trabajo colectivo y dialógico que se produce en su vida diaria es fundamental.

PALABRAS CLAVE: Violencia. Escuela pública. La violencia escolar.

${ }^{1}$ Universidade do Estado do Rio Grande do Norte (UERN), Mossoró - RN - Brasil. Discente do Programa de Pós-Graduação em Ensino. ORCID: https://orcid.org/0000-0003-0236-1531. E-mail: silesiapassos@gmail.com

${ }^{2}$ Universidade do Estado do Rio Grande do Norte (UERN), Mossoró - RN - Brasil. Professor Permanente do Programa de Pós-Graduação em Ensino. ORCID: https://orcid.org/0000-0001-7800-8350. E-mail: maccolle@hotmail.com

${ }^{3}$ Universidade Federal Rural do Semi-Árido (UFERSA), Mossoró - RN - Brasil. Professor Permanente do Programa de Pós-Graduação em Ensino. ORCID: http://orcid.org/0000-0003-3988-3915. E-mail: emerson.medeiros@ufersa.edu.br 
ABSTRACT: The article presents a bibliographical survey on the theme "violence in public schools". This study is based on the analysis of 16 dissertations and theses deposited in the Digital Library of Theses and Dissertations (BDTD). The period from 2012 to 2019 was used as a time frame, crediting the most current academic production on the subject. In the development of the analysis, it was considered, mainly, the objectives of the studies, some understandings about the theme textualized in the research and methodologies used. It was concluded that the theme "violence in public schools" is complex. Its textualized understanding in academic productions needs to be associated with broader social issues. However, it was identified that public schools are able to minimize the different types of violence that occur within them. For this, the collective and dialogical work produced in their daily lives is essential.

KEYWORDS: Violence. Public school. School violence.

\section{Introdução}

Segundo Santos e Rodrigues (2015), a violência na escola é um fenômeno complexo, imbricado de diversos entendimentos e significados que tem marcado o campo educacional, especialmente, as instituições escolares. Para Bauman (2008), o ambiente (sociedade) líquido e moderno está longe de ficar livre de perigos e ameaças, de natureza diversa. Nesse movimento de fluidez, o fenômeno da violência na escola tem se constituído em um campo de estudos de pesquisadores ao se debruçarem sobre a questão para entender as possíveis definições e manifestações que acarretam na violência no ambiente escolar.

Ressaltamos que o presente estudo se filia a uma pesquisa desenvolvida sobre a violência na escola pública no Programa de Pós-Graduação em Ensino da Universidade do Estado do Rio Grande do Norte (POSENSINO/UERN). Movidos pela intenção de pesquisar sobre o tema, iniciamos estudos exploratórios a respeito da produção acadêmica que versa sobre o mote central da dissertação (violência na escola pública). Assim, desenvolvemos esta investigação que se aproxima ao que se denomina na literatura acadêmica educacional de "Estado da Arte”. De acordo com Ferreira (2002, p. 258), essas pesquisas,

[...] são definidas como de caráter bibliográfico, elas parecem trazer em comum o desafio de mapear e discutir, certa produção acadêmica em diferentes campos do conhecimento, tentando responder que aspectos e dimensões vêm sendo destacados e privilegiados em diferentes épocas e lugares, de que forma e em que condições têm sido produzidas certas dissertações de mestrados, teses de doutorados, publicações em periódicos e comunicações em anais de congressos e de seminários.

Com isso, partimos da metodologia investigativa de caráter inventariante e descritivo, evidenciamos o panorama atual da produção acadêmica acerca da violência na escola pública. 
Buscamos registrar, em texto, os objetivos dos estudos, algumas compreensões demarcadas pelos pesquisadores a respeito da violência na escola pública, bem como a dimensão metodológica das investigações. Ressaltamos que as pesquisas denominadas de "Estado da Arte" são caracterizadas,

Por realizarem uma metodologia de caráter inventariante e descritivo da produção acadêmica e cientifica sobre o tema que busca investigar, à luz de categorias e facetas que se caracterizam enquanto tais em cada trabalho e no conjunto deles, sob os quais o fenômeno passa a ser analisado (FERREIRA, 2002, p. 258).

Em outras palavras, entendemos que o "Estado da Arte" se refere a um estudo que mapeia (inventaria) e discute a produção acadêmica sobre um determinado tema em um campo científico específico. Na nossa pesquisa, inventariamos a violência na escola pública, validando as produções científicas brasileiras (teses e dissertações) presentes na Biblioteca Digital de Teses e Dissertações (BDTD). Aludimos, outra vez, que levamos em consideração os objetivos das produções investigadas, algumas compreensões da temática nos textos acadêmicos e as metodologias utilizadas nas produções.

\section{Caminhos investigativos}

Inicialmente, organizamos os procedimentos metodológicos desta pesquisa em três etapas. A primeira etapa foi destinada à realização da seleção das plataformas armazenadoras de trabalhos científicos (Biblioteca Digital de Teses e Dissertações). Na segunda etapa, fizemos as buscas e escolhas dos trabalhos que seriam analisados e, por fim, construímos os dados da pesquisa, creditando a análise das produções a respeito da violência na escola pública.

Novamente frisamos que o mapeamento foi realizado na Biblioteca Digital de Teses e Dissertações (BDTD). A plataforma tem por objetivo integrar, em um único portal, os sistemas de informações de teses e dissertações existentes no país e disponibilizar para os usuários um catálogo nacional de teses e dissertações em texto integral, possibilitando uma forma de busca e acesso a esses documentos.

Com a plataforma escolhida, seguimos para a busca. A pesquisa foi realizada no mês de maio do ano de 2019. Utilizamos como marco temporal o período de 2012 a 2019. Assim, buscamos os trabalhos por meio das palavras-chave: a) "violência na escola" e "indisciplina" e b) "violência na escola" e "currículo". A demarcação do período temporal se fez validando a produção mais atual acerca do tema. No que toca às palavras-chave, consideramos os termos 
que se relacionam aos principais conceitos estudados no nosso trabalho dissertativo (violência na escola pública). Na sequência, organizamos os achados descritos anteriormente.

Quadro 1 - Quantitativo das produções acadêmicas encontradas na BDTD (2012- 2019)

\begin{tabular}{|c|c|c|c|}
\hline Título & Dissertações & Teses & Total \\
\hline - "Violência na escola", & 24 & 05 & 29 \\
\hline - "Indisciplina" & & 05 & 19 \\
\hline $\begin{array}{c}\text { - "Violência na escola", } \\
\text {-"Currículo" }\end{array}$ & 14 & 10 & 48 \\
\hline Total & 38 & & \\
\hline
\end{tabular}

Fonte: Elaborado pelos autores

Na conjugação das palavras-chave "violência na escola" e "indisciplina" (com o uso das aspas), no filtro "título" encontramos o total de 29 (vinte e nove) teses e dissertações - 24 (vinte e quatro) dissertações e 05 (cinco) teses. Com as palavras-chave "violência na escola" e "currículo" (com aspas) no filtro "título" encontramos o total de 19 (dezenove) teses e dissertações - 14 (quatorze) dissertações e 05 (cinco) teses. No geral, encontramos 48 (quarenta e oito) pesquisas dissertativas e doutorais. No entanto, ao considerarmos o foco central do estudo, desenvolvemos a análise de apenas 16 (dezesseis) produções - 13 (treze) dissertações e 03 (três) teses. Na sequência, explanaremos nossos achados.

\section{Violência na Escola Pública - o que apontam as produções acadêmicas (2012 - 2019)?}

Conforme destacamos anteriormente, o presente texto socializa um estudo acerca da produção acadêmica que tematiza a violência na escola pública, com o recorte temporal de 2012 a 2019. Ele se associa ao nosso trabalho dissertativo desenvolvido no Programa de PósGraduação em Ensino (POSENSINO), da Universidade do Estado do Rio Grande do Norte (UERN). A partir deste momento, socializaremos o que encontramos, em termos de pesquisa. O Gráfico 1 evidencia a distribuição das produções acadêmicas, validando os estados e as regiões brasileiras. 
Gráfico 1 - Distribuição das produções acadêmicas sobre violência na escola pública por estados e regiões brasileiras

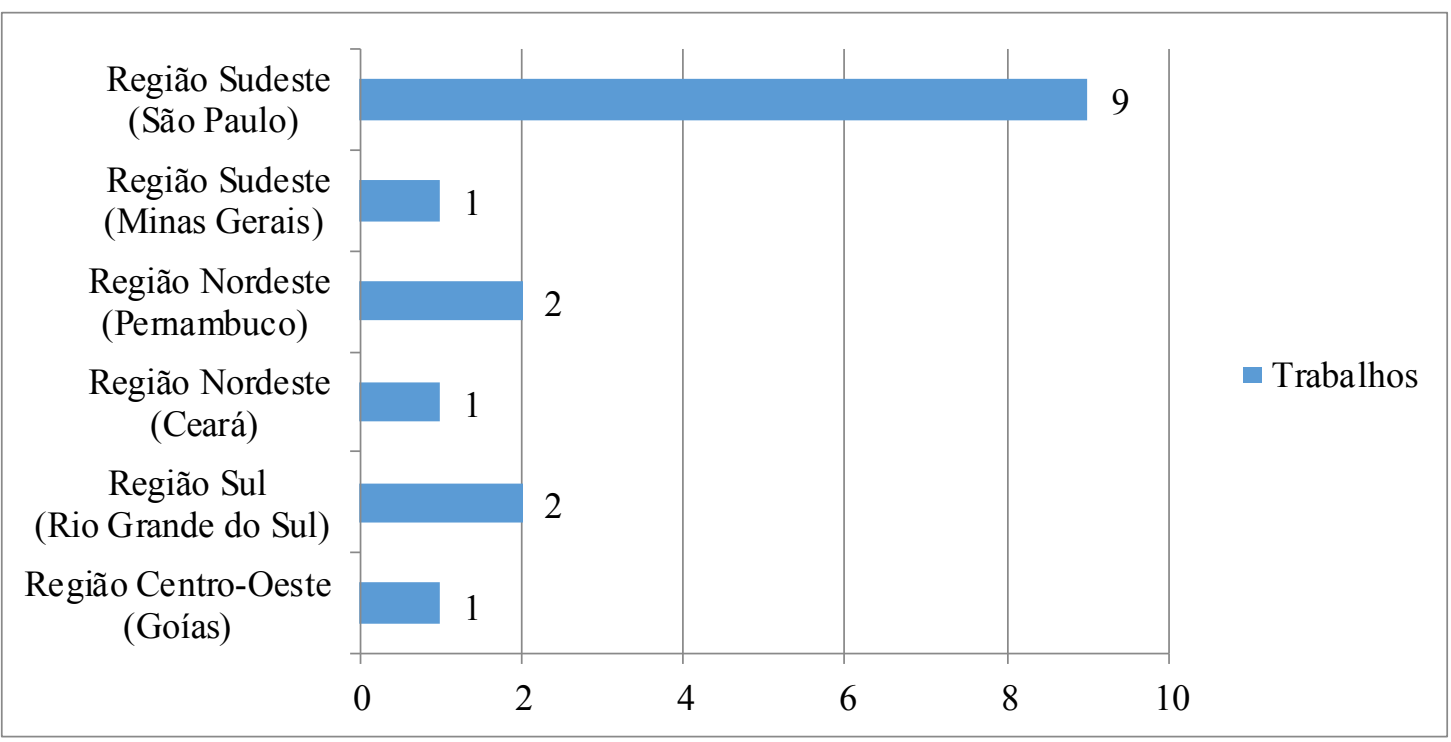

Fonte: Elaborado pelos autores

Destacamos, a partir do que evidencia o Gráfico 1, que há nos achados de nossa pesquisa um número representativo de trabalhos desenvolvidos na Região Sudeste, mais precisamente no Estado de São Paulo. Em termos numéricos, aparece na sequência a Região Nordeste com os Estados de Pernambuco, com 02 (duas) produções, e o Ceará, com 01 (uma) produção, perfazendo 03 (três) estudos. Enfatizamos também a Região Sul, o Estado do Rio Grande do Sul, com 02 (duas) produções, e a Região Centro-Oeste, com 01 (uma) produção no Estado de Goiás.

Ressaltamos que, ao realizarmos o "Estado da Arte" acerca da produção do conhecimento sobre a violência na escola pública, tivemos muitas dificuldades de selecionar as produções que pudessem estar colaborando com a nossa pesquisa, haja vista que a maioria não correspondia ao que queríamos na investigação. Assim, prevaleceram como próximas ao nosso objeto de estudo no mestrado em ensino 16 (dezesseis) produções pesquisadas nos Estados e Regiões expostas no Gráfico 1.

Identificamos que as pesquisas sobre o tema violência na escola pública povoam diferentes instituições de educação superior - públicas e privadas -, bem como se concentram nos programas de pós-graduação de algumas áreas, com maior ênfase na Educação, denotando a carência de investigações na área de Ensino. No Quadro 2, pontificamos a distribuição dos trabalhos por instituição de educação superior. 
Quadro 2 - Distribuição das teses e dissertações por instituição de educação Superior

\begin{tabular}{|l|c|c|c|}
\hline \multicolumn{1}{|c|}{ Universidades } & Teses & Dissertações & $\mathbf{N}^{\mathbf{0}}$ de Trabalhos \\
\hline PUC-SP & 01 & 02 & 03 \\
\hline PUC-GO & 00 & 01 & 01 \\
\hline UNESP & 01 & 03 & 01 \\
\hline FGV - EAESP & 00 & 01 & 01 \\
\hline UNIPAMPA & 00 & 01 & 02 \\
\hline UFPE & 00 & 02 & 01 \\
\hline UNIFOR & 01 & 00 & 01 \\
\hline UFSCar & 00 & 01 & 01 \\
\hline UCS-RS & 00 & 01 & 01 \\
\hline UFJF & 00 & 01 & 01 \\
\hline
\end{tabular}

Fonte: Elaborado pelos autores

Dos 16 (dezesseis) estudos desenvolvidos no período de 2012 a 2019 sobre a violência na escola pública, na pós-graduação de alguns estados do país (São Paulo, Minas Gerais, Pernambuco, Ceará, Rio Grande do Sul e Goiás), enfatizamos que 03 (três) produções se encontram na Pontifícia Universidade Católica de São Paulo (PUC-SP), 04 (quatro) investigações na Universidade Estadual Paulista (UNESP), 01 (um) estudo na Universidade Federal de São Carlos (UFScar), 01 (uma) pesquisa na Escola de Administração de Empresa de São Paulo da Fundação Getúlio Vargas (FGV), 01 (um) trabalho na Pontifícia Universidade Católica de Goiás (PUC-GO), 01 (um) estudo na Universidade Federal do Pampa (UNIPAMPA), 02 (duas) pesquisas na Universidade Federal de Pernambuco (UFPE), 01 (uma) investigação na Universidade de Fortaleza (UNIFOR), 01 (um) estudo na Universidade Federal de Juiz de Fora (UFJF) e 01 (um) trabalho na Universidade de Caxias do Sul (UCS-RS).

De maneira geral, percebemos que há uma ênfase de pesquisas desenvolvidas em instituições públicas de educação superior. Dos 16 (dezesseis) trabalhos analisados, 09 (nove) pertencem a universidades públicas estaduais e federais brasileiras, evidenciando a hegemonia das instituições públicas no âmbito da produção do conhecimento na pós-graduação.

$\mathrm{Na}$ continuidade da apresentação do que inventariamos, o quadro em sequência alude o demonstrativo das produções de teses e dissertações, destacando o título, o objetivo, a metodologia, a instituição, a natureza do estudo, o ano de conclusão e o autor. 
Quadro 3 - Demonstrativo das teses e dissertações sobre violência na escola pública (2012 2019)

\begin{tabular}{|c|c|c|c|c|}
\hline Título & Objeto do Estudo & Metodologia & $\begin{array}{l}\text { Instituição/ } \\
\text { Ano }\end{array}$ & Autor/a \\
\hline $\begin{array}{l}\text { Violência contra a } \\
\text { escola: } \\
\text { Repercussões } \\
\text { Curriculares - o } \\
\text { olhar do Conselho } \\
\text { de Escola numa } \\
\text { escola municipal de } \\
\text { Santo André }\end{array}$ & $\begin{array}{l}\text { Apresentar uma análise } \\
\text { das situações de } \\
\text { violência praticadas } \\
\text { contra a escola, } \\
\text { identificar as ações e } \\
\text { como são abordadas no } \\
\text { currículo }\end{array}$ & $\begin{array}{l}\text { Abordagem qualitativa, } \\
\text { análise documental e } \\
\text { entrevistas } \\
\text { semiestruturadas com } \\
\text { os membros do } \\
\text { Conselho da Escola }\end{array}$ & $\begin{array}{c}\text { Pontifícia } \\
\text { Universidade } \\
\text { Católica de São } \\
\text { Paulo - PUC/SP. } \\
2015 \\
\text { Dissertaç } \\
\text { ão }\end{array}$ & $\begin{array}{l}\text { Marli Luiza de } \\
\text { Sousa }\end{array}$ \\
\hline $\begin{array}{l}\text { Os conflitos em } \\
\text { ambientes } \\
\text { escolares: um olhar } \\
\text { além da superfície }\end{array}$ & $\begin{array}{l}\text { Estudar os conflitos } \\
\text { entre alunos e as } \\
\text { formas de resolução, } \\
\text { através da percepção } \\
\text { dos sujeitos escolares }\end{array}$ & $\begin{array}{l}\text { Revisão de literatura e } \\
\text { investigação qualitativa } \\
\text { com observações e } \\
\text { entrevistas sobre } \\
\text { conflitos entre alunos }\end{array}$ & $\begin{array}{c}\text { Universidade } \\
\text { Estadual Paulista } \\
\text { - UNESP. } \\
2019 \\
\text { Dissertação }\end{array}$ & $\begin{array}{l}\text { Lilian } \\
\text { Rodrigues } \\
\text { Martins } \\
\text { Pereira }\end{array}$ \\
\hline $\begin{array}{lr}\text { Moralidade } & \text { e } \\
\text { violência } & \text { nas } \\
\text { escolas na visão dos } \\
\text { professores }\end{array}$ & $\begin{array}{l}\text { Conhecer e analisar o } \\
\text { que pensam professores } \\
\text { do } 6^{\circ} \text { ano de duas } \\
\text { escolas públicas de } \\
\text { Maringá sobre } \\
\text { violência escolar e } \\
\begin{array}{ll}\text { desenvolvimento da } \\
\text { moralidade humana }\end{array} \\
\end{array}$ & $\begin{array}{ll}\text { Pesquisa } & \text { qualitativa } \\
\text { com } & \text { entrevistas } \\
\text { semiestruturadas }\end{array}$ & $\begin{array}{c}\text { Universidade } \\
\text { Estadual Paulista } \\
\text { - UNESP. } \\
2014 \\
\text { Dissertação }\end{array}$ & $\begin{array}{l}\text { Rodrigo César } \\
\text { Costa }\end{array}$ \\
\hline $\begin{array}{l}\text { Violência na Escola } \\
\text { Pública? O estudo } \\
\text { de uma realidade no } \\
\text { Município ro de } \\
\text { Franca/SP }\end{array}$ & $\begin{array}{l}\text { Analisar as diferentes } \\
\text { manifestações e causas } \\
\text { da violência na escola }\end{array}$ & $\begin{array}{l}\text { Levantamento } \\
\text { bibliográfico } \\
\text { documental nas } \\
\text { delegacias e prefeituras } \\
\text { da região }\end{array}$ & $\begin{array}{c}\text { Universidade } \\
\text { Estadual Paulista } \\
\text { - UNESP. } \\
2015 \\
\text { Dissertação }\end{array}$ & $\begin{array}{l}\text { Marília Borges } \\
\text { Diogo }\end{array}$ \\
\hline $\begin{array}{l}\text { Violência nas } \\
\text { escolas e políticas } \\
\text { públicas: um estudo } \\
\text { sobre a formulação } \\
\text { do Sistema de } \\
\text { Proteção Escolar e } \\
\text { Cidadania }\end{array}$ & $\begin{array}{l}\text { Entender como são } \\
\text { formuladas as políticas } \\
\text { públicas sobre } \\
\text { violência na escola }\end{array}$ & $\begin{array}{l}\text { Revisão da literatura e } \\
\text { estudo de caso sobre o } \\
\text { processo de formulação } \\
\text { do Sistema de Proteção } \\
\text { Escolar e Cidadania }\end{array}$ & $\begin{array}{c}\text { Escola de } \\
\text { Administração de } \\
\text { Empresas de São } \\
\text { Paulo-FGV. } \\
2015 \\
\text { Dissertação }\end{array}$ & $\begin{array}{l}\text { Patrícia de } \\
\text { Oliveira } \\
\text { Nogueira } \\
\text { Pröglhö }\end{array}$ \\
\hline $\begin{array}{lr}\text { Educação } & \text { em } \\
\text { valores: } & \text { solução } \\
\text { para a violência e } \\
\text { indisciplina na } \\
\text { escola? }\end{array}$ & 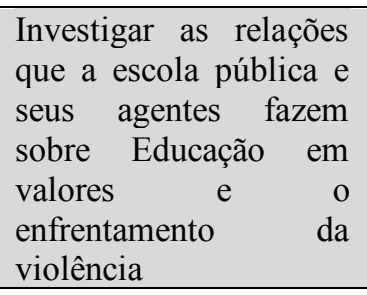 & $\begin{array}{l}\text { Estudo descritivo com } \\
\text { abordagem qualitativa }\end{array}$ & $\begin{array}{c}\text { Universidade } \\
\text { Estadual Paulista } \\
\text { - UNESP. } \\
2014 \\
\text { Tese }\end{array}$ & $\begin{array}{l}\text { Juliana } \\
\text { Aparecida } \\
\text { Matias Zechi }\end{array}$ \\
\hline $\begin{array}{lr}\text { Mediação } & \text { de } \\
\text { conflitos } & \text { como } \\
\text { estratégia } & \text { de } \\
\text { prevenção } & \text { da } \\
\text { violência na escola }\end{array}$ & $\begin{array}{l}\text { Investigar as ações para } \\
\text { a prevenção da } \\
\text { violência na escola }\end{array}$ & $\begin{array}{l}\text { Curso de extensão de } \\
40 \text { horas com um grupo } \\
\text { de professores do } 5^{\circ} \text { ao } \\
9^{\circ} \text { ano, com êfase na } \\
\text { pesquisa } \\
\text { intervencionista, tipo } \\
\text { pedagógica }\end{array}$ & $\begin{array}{c}\text { Universidade } \\
\text { Federal do Pampa } \\
\text { - UNIPAMPA. } \\
2018 \\
\text { Dissertação }\end{array}$ & $\begin{array}{l}\text { Ivonete } \\
\text { Afonso Jodar }\end{array}$ \\
\hline \begin{tabular}{lr}
\multicolumn{2}{l}{ Construção coletiva } \\
de regras r e \\
resoluções & de \\
conflitos: & \\
contribuições & para o
\end{tabular} & $\begin{array}{l}\text { Investigar se ações } \\
\text { como a constituição } \\
\text { coletiva de regras e a } \\
\text { resolução de conflitos } \\
\text { contribuem } \quad \text { para }\end{array}$ & $\begin{array}{l}\text { Encontros de formação } \\
\text { com os professores e } \\
\text { coleta de dados por } \\
\text { áudios e textos com } \\
\text { abordagem qualitativa }\end{array}$ & $\begin{array}{c}\text { Pontifícia } \\
\text { Universidade } \\
\text { Católica de São } \\
\text { Paulo - PUC/SP. } \\
2017 \\
\end{array}$ & $\begin{array}{l}\text { Eliane } \\
\text { Pinheiro } \\
\text { Fernandes }\end{array}$ \\
\hline
\end{tabular}




\begin{tabular}{|c|c|c|c|c|}
\hline $\begin{array}{ll}\text { enfrentamento da } \\
\text { violência entre } \\
\text { alunos } \\
\end{array}$ & $\begin{array}{l}\text { diminuir a violência na } \\
\text { escola }\end{array}$ & na análise do material & Dissertação & \\
\hline $\begin{array}{l}\text { Violência e Escola: } \\
\text { perspectivas } \\
\text { desafios }\end{array}$ & $\begin{array}{l}\text { Conhecer e analisar a } \\
\text { violência no contexto } \\
\text { da escola em suas } \\
\text { diversas formas de } \\
\text { manifestação e as } \\
\text { medidas utilizadas pela } \\
\text { escola em reu } \\
\text { enfrentamento }\end{array}$ & $\begin{array}{l}\text { Pesquisa qualitativa, } \\
\text { observação in loco, } \\
\text { análise documental, } \\
\text { entrevistas com o grupo } \\
\text { gestor da escola e a } \\
\text { realização } \\
\text { de grupos } \\
\text { focais com alunos e } \\
\text { professores }\end{array}$ & $\begin{array}{c}\text { Pontifícia } \\
\text { Universidade } \\
\text { Católica de Goiás } \\
\text { - PUC/GO. } \\
2012 \\
\text { Dissertação }\end{array}$ & $\begin{array}{l}\text { Cirlene Maria } \\
\text { da Silva }\end{array}$ \\
\hline $\begin{array}{l}\text { Gestão escolar } \\
\text { democrática: } \\
\text { relações de poder } \\
\text { como mediação na } \\
\text { prevenção e } \\
\text { enfrentamento das } \\
\text { violências na escola }\end{array}$ & $\begin{array}{l}\text { Analisar as ações } \\
\text { desenvolvidas pela } \\
\text { gestão escolar em uma } \\
\text { perspectiva } \\
\text { democrática, visando o } \\
\text { combate e a prevenção } \\
\text { da violência na escola } \\
\text { pública }\end{array}$ & $\begin{array}{l}\text { Pesquisa qualitativa } \\
\text { etnográfica com estudo } \\
\text { em uma escola pública } \\
\text { de Pernambuco, com } \\
\text { entrevistas, } \\
\text { observações e análise } \\
\text { documental }\end{array}$ & $\begin{array}{l}\text { Universidade } \\
\text { Federal de } \\
\text { Pernambuco } \\
\text { UFPE. } \\
\quad 2013 \\
\quad \text { Dissertação }\end{array}$ & $\begin{array}{l}\text { Karla Cristian } \\
\text { da Silva }\end{array}$ \\
\hline $\begin{array}{lr}\text { Indisciplina } & \mathrm{e} \\
\text { violência na escola: } \\
\text { concepções } \\
\text { discursos } \\
\text { educadores }\end{array}$ & $\begin{array}{l}\text { Analisar o discurso de } \\
\text { educadores a respeito } \\
\text { do conflito, da } \\
\text { indisciplina } \\
\text { e/ou violência na escola } \\
\text { e investigar se essas } \\
\text { concepções se refletem } \\
\text { em suas práticas }\end{array}$ & $\begin{array}{l}\begin{array}{l}\text { Pesquisa qualitativa, } \\
\text { com análise }\end{array} \\
\text { documental } \\
\text { levantamento de casos } \\
\text { de indisciplina e } \\
\text { violência. Entrevistas } \\
\text { com a equipe gestora } \\
\text { da escola e professores }\end{array}$ & $\begin{array}{c}\text { Universidade } \\
\text { Federal de São } \\
\text { Carlos - UFSCar. } \\
2016 \\
\text { Dissertação }\end{array}$ & $\begin{array}{l}\text { Ariel Cristina } \\
\text { Gatti Vergna }\end{array}$ \\
\hline $\begin{array}{l}\text { Violência nas } \\
\text { Escolas: reflexões a } \\
\text { partir do cotidiano } \\
\text { da RME de Caxias } \\
\text { do Sul-RS }\end{array}$ & $\begin{array}{l}\text { Compreender os fatores } \\
\text { geradores, bem como } \\
\text { as manifestações de } \\
\text { violência na Rede } \\
\text { Municipal de Ensino, } \\
\text { com base nos alunos }\end{array}$ & $\begin{array}{l}\text { Análise de dados do } \\
\text { Comitê Interno de } \\
\text { Prevenção a Violência } \\
\text { na escola, estado da } \\
\text { arte sobre a temática e } \\
\text { análise de } 132 \\
\text { questionários de alunos }\end{array}$ & $\begin{array}{l}\text { Universidade de } \\
\text { Caxias do Sul - } \\
\text { UCS/RS. } \\
2017 \\
\text { Dissertação }\end{array}$ & $\begin{array}{l}\text { Rubia } \\
\text { Paula } \\
\text { Bamberg }\end{array}$ \\
\hline $\begin{array}{l}\text { O território da } \\
\text { incivilidade na } \\
\text { manifestação da } \\
\text { violência escolar: } \\
\text { um olhar nas } \\
\text { violências } \\
\text { intramurais }\end{array}$ & $\begin{array}{l}\text { Expor e analisar o } \\
\text { fenômeno da violência } \\
\text { e suas ramificações } \\
\text { dentro do espaço } \\
\text { escolar se utilizando } \\
\text { dos olhares da gestão } \\
\text { escolar, coordenação } \\
\text { pedagógica, docentes e } \\
\text { discentes. }\end{array}$ & $\begin{array}{l}\text { Pesquisa qualitativa e } \\
\text { revisão bibliográfica, } \\
\text { questionário com } \\
\text { perguntas abertas e } \\
\text { fechadas }\end{array}$ & $\begin{array}{l}\text { Universidade } \\
\text { Federal de } \\
\text { Pernambuco- } \\
\text { UFPE. } \\
2016 \\
\text { Dissertação }\end{array}$ & $\begin{array}{l}\text { Gustavo } \\
\text { Rodrigues } \\
\text { Silva }\end{array}$ \\
\hline $\begin{array}{l}\text { A escola às avessas: } \\
\text { sujeito e instituição } \\
\text { escolar no contexto } \\
\text { da violência do } \\
\text { bullying }\end{array}$ & $\begin{array}{lr}\text { Investigar } & \text { a } \\
\text { manifestação } & \text { do } \\
\text { bullying nas escolas e a } \\
\text { relação que } & \text { estabelece } \\
\text { com o } & \text { discurso } \\
\text { capitalista } & \text { pós- } \\
\text { moderno, a } & \text { cultura } \\
\text { escolar } & \text { e } \\
\text { subjetividade } & \text { dos } \\
\text { sujeitos provocadores }\end{array}$ & $\begin{array}{l}\text { Pesquisa qualitativa de } \\
\text { cunho bibliográfico e } \\
\text { documental (análise das } \\
\text { fichas ou ocorrência } \\
\text { disciplinar) }\end{array}$ & $\begin{array}{l}\text { Universidade de } \\
\text { Fortaleza- } \\
\text { UNIFOR/CE. } \\
2015 \\
\text { Tese }\end{array}$ & $\begin{array}{l}\text { Marcos } \\
\text { Aurélio } \\
\text { Patrício } \\
\text { Ribeiro }\end{array}$ \\
\hline $\begin{array}{l}\text { Violência } \\
\text { Tolerância na } \\
\text { Escola: perspectiva } \\
\text { das produções } \\
\text { acadêmicas }\end{array}$ & $\begin{array}{l}\text { Identificar como a } \\
\text { violência na escola tem } \\
\text { sido estudada } \\
\text { cientificamente com o } \\
\text { objetivo } \\
\text { compreender }\end{array}$ & $\begin{array}{l}\text { Pesquisa qualitativa de } \\
\text { cunho bibliográfico }\end{array}$ & $\begin{array}{c}\text { Pontifícia } \\
\text { Universidade } \\
\text { Católica de São } \\
\text { Paulo - PUC/SP. } \\
2015 \\
\text { Tese }\end{array}$ & $\begin{array}{l}\text { Tânia } \\
\text { Marsiglia }\end{array}$ \\
\hline
\end{tabular}

RPGE- Revista on line de Política e Gestão Educacional, Araraquara, v. 25, n. 3, p. 2843-2860, set./dez. 2021. e-ISSN: 1519-9029 DOI: https://doi.org/10.22633/rpge.v25i3.15343 


\begin{tabular}{|c|c|c|c|c|}
\hline & $\begin{array}{l}\text { violência na escola tem } \\
\text { sido tolerada e se tal } \\
\text { tolerância tem sido alvo } \\
\text { dos pesquisadores }\end{array}$ & & & \\
\hline $\begin{array}{lr}\text { Estratégia da gestão } \\
\text { escolar } & \text { de } \\
\text { enfrentamento } & \text { a } \\
\text { violência: } & \text { uma } \\
\text { análise } & \text { da } \\
\text { implantação } & \text { do } \\
\text { PROERD numa } \\
\text { escola na rede } \\
\text { pública estadual no } \\
\text { Amazonas }\end{array}$ & $\begin{array}{l}\text { Analisar quais as ações } \\
\text { da gestão escolar para o } \\
\text { enfrentamento da } \\
\text { violência escolar diante } \\
\text { do comportamento } \\
\text { agressivo de } \\
\text { adolescentes e jovens }\end{array}$ & $\begin{array}{l}\text { Pesquisa qualitativa e } \\
\text { aplicação } \\
\text { questionário de } \\
\text { perguntas abertas }\end{array}$ & $\begin{array}{l}\text { Universidade } \\
\text { Federal de Juiz de } \\
\text { Fora - UFJF. } \\
2015 \\
\text { Dissertação }\end{array}$ & $\begin{array}{l}\text { Rosângelo } \\
\text { Fernandes de } \\
\text { Assis }\end{array}$ \\
\hline
\end{tabular}

Fonte: Elaborado pelos autores

No âmago das produções que enunciam o fenômeno da violência na escola pública, foi observado que, de forma quase unânime, houve uma preocupação com o fenômeno da violência escolar, levando-nos ao entendimento de que todas as produções traçaram suas compreensões acerca da violência na escola, como também formas de estratégias para o seu enfrentamento.

O primeiro trabalho, "Violência contra a Escola: repercussões curriculares - o olhar do Conselho de Escola numa escola municipal de Santo André", teve como objetivo principal apresentar uma análise das situações de violência praticadas contra a escola, bem como identificar as ações e como são abordadas no currículo escolar. Para Sousa (2015, p. 129),

A elaboração de um projeto coletivo de escola, na perspectiva da gestão democrática, é uma possibilidade de encaminhamento para o enfrentamento da violência na escola [...] com propostas de ações que envolvam a comunidade e dialoguem abertamente com a população sobre os problemas que obstaculizem a concretização desse projeto.

O estudo de Sousa (2015) vem abrir um espaço para criação de projetos coletivos que envolvam a comunidade como uma possibilidade de enfrentamento do fenômeno da violência escolar, afirmando que o diálogo é a peça fundamental para a concretude de um projeto que possa abarcar direta ou indiretamente os variados sujeitos no contexto da escola pública.

O segundo trabalho é uma dissertação intitulada "Os conflitos em ambientes escolares: um olhar além da superfície". Teve como objetivo estudar os conflitos entre alunos e as formas de resolução por meio da percepção dos sujeitos escolares, assim como por intermédio da revisão literária e dos documentos escolares, para propor possibilidades à aprendizagem e ao desenvolvimento das relações sociais, no sentido de melhorar as relações no ambiente da escola. Quanto ao estudo, compreendemos que: 
$\mathrm{O}$ acesso à reflexão individual e coletiva atrelada a uma prática dialógica e ética, que contemple os diferentes fatores que incidem na relação entre alunos, poderá propiciar aos indivíduos um pensar e um posicionamento crítico sobre a realidade, de sorte a possibilitar o enfrentamento às manifestações de violência e resolução de conflito, fundamentada no diálogo, o que incidirá o aprimoramento das relações no interior da escola (PEREIRA, 2019, p. 297).

É evidente que as duas produções dissertativas destacadas anteriormente apresentam formas de estratégias para o enfrentamento da violência no cenário escolar público. Sousa (2015) e Pereira (2019) chamam a atenção para uma prática que privilegie o diálogo entre os sujeitos escolares, somando-se a uma possibilidade de enfrentamento à violência na escola pública.

Costa (2014), com a pesquisa "Moralidade e Violência nas escolas na visão dos professores", reforça o pensamento dos autores, pois apresenta uma análise para a manifestação da violência na escola de forma simbólica, verbal e física. O estudo objetiva conhecer o que pensam os professores sobre a violência escolar e o desenvolvimento da moralidade e suas possíveis relações. A pesquisa traz ainda uma breve discussão acerca de violência na escola, indisciplina e bullying, além de discutir as relações entre família e escola.

Costa (2014, p. 7) afirma que:

A teoria do desenvolvimento moral (teoria e prática) é fundamental para a promoção de diálogos que promovam o amadurecimento de conceitos como: dignidade, justiça, bondade, solidariedade e respeito aos outros seres humanos como forma de promover uma educação pacificadora, de forma a anular a violência nas escolas.

Não diferentemente das duas primeiras dissertações dialogadas, o estudo de Costa (2014) traz a promoção do diálogo para o amadurecimento de conceitos referentes à justiça, à dignidade e ao respeito que possam favorecer uma educação pacificadora no convívio escolar, especialmente no contexto da escola pública.

Nessa linha de pensamento, despertou-nos atenção o trabalho de Diogo (2015), nominado "Violência na Escola Pública? o estudo de uma realidade no Município de Franca/SP". O estudo teve como objetivo central analisar as diferentes manifestações e causas da violência na escola, bem como as estratégias adotadas pelas instituições para lidar com o problema. A autora vê a violência como uma questão histórica, um advento do capitalismo, marcado pela relação de exploração e opressão do homem pelo homem. Para Diogo (2015, p. 20), "a violência se faz presente em nossas vidas de forma coletiva ou individual, tornando o tema sempre atual e deixando muitas questões”. A autora concluiu que a escola pública 
precisa se abrir para a participação da comunidade exterior, buscando a união de pais e professores, no fito de melhores soluções para as diversas questões que estão inseridas na instituição escolar.

Aduzimos que Sousa (2015), Pereira (2019), Costa (2014) e Diogo (2015), apresentam em suas produções dissertativas possibilidades focadas no diálogo na superação da violência na escola pública. Tais estudos buscam conhecer, por meio dos professores, a compreensão da violência, já que são eles os profissionais que estão no dia a dia com os alunos traçando estratégias de participação com a comunidade escolar. Esse fato ratifica que a participação da comunidade exterior à escola pública nas ações escolares é mais eficaz se construída com o diálogo.

A dissertação de Pröglhöf (2015), "Violência nas escolas e políticas públicas: um estudo sobre a formação do sistema de Proteção Escolar e Cidadania", investigou como o poder público formula as políticas públicas para conter o problema da violência na escola. $\mathrm{O}$ trabalho tem ampla revisão de literatura, aliada a um estudo de caso sobre o processo de formulação do Sistema de Proteção Escolar e Cidadania, criado em 2009, pelo governo do Estado de São Paulo. A pesquisadora pontifica que é a partir da década de 1980 que se começa a verificar no país, de forma mais acentuada, a preocupação com relação à violência na escola. Para ela, a violência no contexto escolar é um tema complexo, nas diversas definições e interpretações. A pesquisa concluiu que grande parte das questões da violência nas escolas públicas é indissociável de problemas mais amplos, sendo imprescindível a articulação entre os diversos setores e, sobretudo, a vontade e o comprometimento político por parte do governo para traçar meios de solução.

Zechi (2014), em sua tese intitulada "Educação em valores: solução para a violência e a indisciplina na escola?", investigou as relações da escola pública e o que seus agentes fazem sobre a educação em valores e o enfrentamento da violência e da indisciplina escolar e qual o tipo de formação eles têm recebido para atuar com o tema no âmbito escolar. Neste contexto, a autora pondera o papel do professor no enfrentamento da violência escolar. Para a autora, "professores, coordenadores, pedagogos e diretores de escola, além da responsabilidade de ensinar, precisam aprender a prevenir a violência e a indisciplina na sala de aula e não a reproduzi-las ou potencializá-las" (ZECHI, 2014, p. 12). Com a pesquisa, observamos que há uma deficiência na formação inicial dos professores para lidar com situações cotidianas de tensões e conflitos na escola pública, sendo esse o grande desafio a ser superado pelos profissionais da Educação. 
A pesquisa de Jodar (2018), "Mediação de conflitos como estratégia de prevenção de violência na escola", objetivou executar a formação de mediadores para atuar nas situações de conflito a partir de uma cultura de diálogo, de respeito e de paz. A pesquisadora considera a violência na escola pública "um desafio social a ser enfrentado devido à complexidade de tipos existentes e de suas inúmeras manifestações" (JODAR, 2018, p. 16). Para Jodar (2018, p. 80),

A mediação de conflitos, assim como a violência na escola, são temas de extrema importância e detectá-los é uma forma de enfrentar o problema que exige autocontrole, maturidade e principalmente postura adequada para cada situação vivenciada.

As três pesquisas apresentadas anteriormente se entrelaçam nos discursos da comunidade escolar e buscam uma articulação com diversos setores que formam a educação e a sociedade, reivindicando comprometimento do poder público e dos professores, gestores, coordenadores pedagógicos, entre outros, para sanar o problema da violência na escola. Tal problema se minimiza ou encontra caminhos para solução quando é pensado coletivamente e contextualmente.

O trabalho de Fernandes (2017), "Construção coletiva de regras e resoluções de conflitos: contribuições para o enfrentamento da violência entre os alunos", enfatizou a violência na escola, especificamente os episódios de agressão entre os estudantes. A pesquisa se endereçou a investigar se ações como a constituição coletiva de regras e a resolução de conflitos contribuem na diminuição dos episódios de violência e na melhoria da qualidade das relações na sala de aula entre os alunos.

Segundo Fernandes (2017), a violência (aliada ao fracasso escolar e o analfabetismo), aparece na mídia como o principal problema da educação pública brasileira. Para a autora, os episódios de violência na escola têm sido tema bastante discutido pelos professores, principalmente, quando tratam da agressão física ou verbal entre alunos, da depredação de prédios e materiais, da criminalidade e dos conflitos por tráfico de drogas no entorno da escola (em especial da escola pública). A pesquisadora salienta que quem mais conhece esse problema são os educadores, os quais vivenciam tal realidade no ambiente diário de atuação profissional.

O estudo, "Violência e Escola: perspectivas e desafios", discorre sobre a relação "violência e escola", entendida em uma perspectiva de totalidade, como uma manifestação da questão social gestada na relação "capital e trabalho". A pesquisa teve como objetivo primordial conhecer e analisar a violência no contexto da escola em suas diversas formas de 
manifestação e as medidas utilizadas pela escola em seu enfrentamento. Silva (2012) aponta algumas estratégias ao combate à violência no contexto escolar, a saber: o diálogo, o respeito às diferenças e a interação entre os próprios alunos. Ela complementa:

$\mathrm{O}$ maior desafio posto às escolas consiste em mostrar aos alunos oportunidades e apostar na capacidade de eles realizarem as suas ideias. Eles são capazes de assumir responsabilidade, negociar, planejar e promover o que é de interesse. O lugar da escola, como fonte privilegiada de mediação, assim como a família possibilita uma atuação ampla no campo da prevenção da violência. Mas é necessário que se estabeleça uma relação respeitosa com os jovens (SILVA, 2012, p. 92).

Silva (2013), no estudo "Gestão Escolar Democrática: relações de poder como mediação na prevenção e enfrentamento da violência”, analisou as ações desenvolvidas pela gestão escolar em uma perspectiva democrática, visando o combate e a prevenção da violência na escola pública. Nos termos de Silva (2013, p. 142-143),

Para que efetivamente haja mudança, compreendemos que requer que a gestão escolar aja em função da democratização das relações de poder no interior das organizações. É imprescindível se considerar a importância do poder de cada sujeito, especialmente dos estudantes, envolvê-los nos processos de decisão e elaboração de forma a serem seguidos como forma de prevenir as indisciplinas e construir uma consciência cidadã que desconstrua essa cultura onde a violência se cola como principal mecanismo de reivindicação. [...] uma escola efetivamente democrática que educa para a cidadania não está imune às violências, mas encontra em suas manifestações indícios de que precisa com mais intensidade dialogar com seus sujeitos, refletir suas práticas e reorientar o caminho em direção ao cumprimento de sua função educativa e social.

O trabalho de Silva (2013), tal como os estudos de Silva (2012) e Fernandes (2017), demarca que as ações coletivas, com ênfase na participação de diferentes sujeitos da escola, ajudam a coibir os episódios de violência no âmbito escolar, violência entendida como manifestações da questão social (desigualdades) geradas pelo capital. Nesse lastro, aludimos sobre a importância da gestão democrática na escola pública para impulsionar ações reflexivas aos sujeitos no espaço educativo.

O estudo, "Indisciplina e Violência na Escola: concepções e discursos de educadores", de Vergna (2016), teve como objetivo analisar o discurso de educadores de uma escola estadual do interior de São Paulo sobre as compreensões a respeito do conflito, da indisciplina e/ou violência na escola e investigar se essas concepções refletem em suas práticas quando lidam com as ocorrências desses eventos em seu espaço de trabalho. A pesquisa concluiu que na escola existia a discussão da valorização do diálogo, porém, por trás de tal concepção, 
ainda estão implícitas e enraizadas as várias relações de poder que se desenvolvem dentro do espaço escolar, tanto em relação aos alunos e professores, como em relação aos docentes e à gestão escolar.

A produção de Bamberg (2017), "Violência nas Escolas: reflexões a partir do cotidiano da RME de Caxias do Sul - RS”, visou compreender a manifestação da violência nas escolas públicas municipais a partir da visão dos estudantes. A pesquisa também realizou o "Estado da Arte" sobre o tema, evidenciando a carência de estudos sobre a violência na escola na perspectiva dos estudantes. O trabalho em questão constatou as manifestações de violência que acabam sendo neutralizadas no cotidiano da escola. Outra constatação foi a resistência, por parte de algumas escolas, para abrir as portas para que suas realidades fossem investigadas. A pesquisa enfatizou a ausência de qualificação da escola pública para lidar com o fenômeno da violência.

Silva (2016), em sua dissertação "O território da incivilidade na manifestação da violência na escola: um olhar nas violências intramurais", objetivou expor e analisar o fenômeno da violência e suas ramificações dentro do espaço escolar público, por meio dos olhares da direção escolar, da coordenação pedagógica, dos docentes e dos discentes de duas instituições de ensino público na região metropolitana do Município de Recife, Pernambuco. O autor constatou que:

A violência é um fenômeno próprio à humanidade, um processo que sempre foi debatido nas principais instâncias, mas que até o momento se torna impossível sua erradicação, apenas um controle através de aparelhos muitas vezes repressivos e também violentos (SILVA, 2016, p. 129).

A pesquisa apontou a impossibilidade de uma extinção no trato das dinâmicas de violência escolar. A violência, de maneira geral, precisa ser rebatida, seja a violência física ou a cultural, como forma de enfrentamento no espaço educacional.

A tese de Ribeiro (2015), "A Escola às Avessas: sujeito e instituição escolar no contexto da violência do Bullying”, abordou o tema da violência na escola focalizando o bullying, investigando sua manifestação na escola e sua relação com o discurso capitalista pós-moderno, a cultura escolar e a subjetividade dos sujeitos (provocadores), praticantes do bullying. O autor reforça que "para compreender a escola é preciso saber como funciona a sociedade em que ela está inserida" (RIBEIRO, 2015, p. 44).

Em sua conclusão, Ribeiro (2015) aponta a escola como um espaço de enlaçamento, podendo ter um laço civilizador ou, por outro lado, um laço social perverso. Na perspectiva do autor, a escola deveria ser um lugar que respeita os ímpetos dos estudantes de forma que 
possa trazer no enlaçamento a civilidade dentro do ambiente escolar, um "lugar para aprender e se desenvolver [...], um espaço de lazer e de preparação para o trabalho" (RIBEIRO, 2015, p. 165).

O estudo doutoral de Marsiglia (2015), "Violência e Tolerância na Escola: perspectiva das produções acadêmicas", se desenvolveu considerando o conjunto de produções acadêmicas sobre o tema, a fim de identificar como a violência na escola tem sido estudada cientificamente. $\mathrm{O}$ objetivo da tese foi compreender como a violência tem sido tolerada e se tal tolerância tem sido alvo de preocupação por parte dos pesquisadores. Para a autora, "a violência instaurada vai além do aspecto físico e se revela igualmente na insensibilidade frente ao observado" (MARSIGLIA, 2015, p. 90). Ao concluir o estudo, a pesquisadora informa que "as pesquisas oferecem contribuições significativas para o aprofundamento das análises sobre o fenômeno da violência na escola que por ser um fenômeno multifacetado demanda uma pluralidade de estudos e de enfoques" (MARSIGLIA, 2015, p. 90).

A produção dissertativa de Assis (2015), "Estratégias da Gestão Escolar de enfrentamento a violência: uma análise da implantação do PROERD em uma escola na rede pública do Estado do Amazonas”, textualizou como objetivo principal analisar as ações da gestão escolar para o enfrentamento à violência na escola diante do comportamento agressivo dos alunos. O estudo mostrou a importância de se pensar estratégias para o enfrentamento à violência escolar. Nas palavras de Assis (2015, p. 68),

A escola por ser um espaço difusor de cultura e informação tem condições de traçar estratégias de promoção juntamente com alunos e professores. Com ações que possam elevar a autoestima do alunado, promovendo junto com eles o enfrentamento à violência na escola.

No conjunto de trabalhos analisados, percebemos que o tema "violência na escola pública” é complexo. Sua compreensão necessita estar associada às questões de cunho social mais amplo. No entanto, identificamos que a escola tem condições de minimizar os diferentes tipos de violência que se sucede em seu interior. Para isso, é essencial o trabalho coletivo e dialógico produzido em seu cotidiano. Também enfatizamos, como fruto da análise, que ela necessita, permanentemente, do apoio de diferentes setores (quer a nível educacional, quer na dimensão social) para atuar de forma exitosa no combate à manifestação da violência. 


\section{Considerações finais}

Conforme destacamos em momento antecedente, o presente estudo, de cunho bibliográfico, atentou à análise do conjunto de 16 (dezesseis) dissertações e teses depositadas na BDTD sobre o tema "violência na escola pública". A pesquisa validou, principalmente, os objetivos das investigações, algumas compreensões acerca do tema e as metodologias utilizadas nos estudos.

A partir dos trabalhos analisados, entendemos que os objetivos das pesquisas, geralmente, estão relacionados à busca de compreensão da violência na escola e seus agravantes, bem como de seus enfrentamentos para coibir os conflitos e as práticas que levam à violência. São recorrentes nesses estudos o debate sobre "conflitos" e "indisciplina".

No que toca à compreensão da violência na escola pública, entendemos que na maioria dos estudos a violência é situada como um tema complexo, com várias significações e entendimentos e com possibilidades de enfrentamento por meio do diálogo com a gestão escolar, os professores e os alunos para debater as práticas de violência no ambiente escolar.

Em relação às questões metodológicas, prevaleceu a pesquisa qualitativa, a qual se materializa com diferentes técnicas de produção de dados, dentre elas, destacam-se a entrevista semiestruturada, o grupo focal, o questionário, a análise bibliográfica, a análise documental e a observação.

Concluímos que é inegável a relevância das discussões postas nas pesquisas no que tange ao tema violência na escola pública. As produções inventariadas nos possibilitaram a reflexão da referida temática, destacando pontos importantes como o diálogo e o trabalho coletivo como dispositivos para minimizar a violência no contexto escolar. Assim, reafirmamos a importância do tema tão presente no contexto atual, o qual ainda requer novos olhares que vislumbrem alternativas para uma cultura de paz no fito de sua superação.

Por último, demarcamos a importância do desenvolvimento de pesquisas sobre a violência na escola pública nos Programa de Pós-Graduação em Ensino. Vimos, a partir do levantamento bibliográfico construído, que a maior parte das investigações acerca do tema se concentra na pós-graduação da área de Educação. Acreditamos que o estudo sobre a violência na escola pública, com ênfase na área de ensino, possibilita demarcar o tema no âmbito da escola, principalmente no contexto da sala de aula. 


\section{REFERÊNCIAS}

ASSIS, R. F. Estratégias da gestão escolar de enfrentamento a violência: uma análise da implementação do PROERD em uma escola na rede pública Estadual. 2015. 78 f. Dissertação (Mestrado em Educação) - Universidade Federal de Juiz de Fora, Juiz de Fora, 2015.

BAMBERG, R. P. Violência nas escolas: reflexões a partir do cotidiano da RME de Caxias do Sul - RS. 2017. 141 f. Dissertação (Mestrado em Educação). Universidade de Caxias do Sul, Caxias do Sul, 2017.

BAUMAN, Z. Medo Líquido. Trad. Carlos Alberto Medeiros. Rio de Janeiro: Jorge Zahar, 2008.

COSTA, R. C. Moralidade e violência nas escolas na visão dos professores. 2014. 106 f. Dissertação (Mestrado em Psicologia) - Universidade Estadual Paulista, Assis, 2014.

DIOGO, M. B. Violência na escola pública? O estudo de uma realidade no município de Franca/SP. 2015. 106 f. Dissertação (Mestrado em Serviço Social) - Universidade Estadual Paulista, Franca, 2015.

FERNANDES, E. P. Construção coletiva de regras e resoluções de conflitos: contribuições para o enfrentamento da violência entre alunos. 2017. 164 f. Dissertação (Mestrado em Educação: Psicologia em Educação). Pontifícia Universidade Católica de São Paulo, São Paulo, 2017.

FERREIRA, N. S. A. As pesquisas denominadas "estado da arte". Educação \& Sociedade, v. 23, n. 79, p. 257-272, ago. 2002.

JODAR, I. A. Mediação de conflitos como estratégia de prevenção da violência na escola. 2018. 91 f. Dissertação (Mestrado em Educação). Universidade Federal do Pampa, Bagé, 2018.

MARSIGLIA, T. Violência e tolerância na escola: perspectiva das produções acadêmicas. 2015. 198 f. Tese (Doutorado em Educação) - Pontifícia Universidade Católica de São Paulo, São Paulo, 2015.

PEREIRA, L. R. M. Os conflitos em ambientes escolares: um olhar além da superfície. 2019. 353 f. Dissertação (Mestrado profissional em docência para educação Básica) Universidade Estadual Paulista, Bauru, 2019.

PRÖGLHÖF, P. O. N. Violência nas escolas e políticas públicas: um estudo do Sistema de Proteção Escolar e Cidadania. 2015. 171 f. Dissertação (Mestrado em Administração Pública) - Escola de Administração de Empresas de São Paulo, Fundação Getúlio Vargas, São Paulo, 2015 .

RIBEIRO, M. A. P. A escola às avessas: sujeitos e instituição escolar no contexto da violência do bullying. 2015. 174 f. Tese (Doutorado em Psicologia) - Universidade de Fortaleza, Fortaleza, 2015. 
SANTOS, J. M. C. T.; RODRIGUES, M. K. S. Violência na escola: sentidos no contexto da prática. Pesquisa em Foco, São Luís, v. 20, n. 2, p. 187-213. 2015.

SILVA, C. M. Violência e escola: perspectiva e desafios. 2012. 115 f. Dissertação (Mestrado em Serviço Social) - Pontifícia Universidade Católica de Goiás, Goiânia, 2012.

SILVA, G. R. O território da incivilidade na manifestação da violência escolar: um olhar nas violências intramurais. 2016. 154 f. Dissertação (Mestrado em Geografia) - Universidade Federal de Pernambuco - UFPE, 2016.

SILVA, K. C. Gestão escolar democrática: relações de poder como mediação na prevenção e enfrentamento das violências na escola. 2013. 154 f. Dissertação (Mestrado em Educação). Universidade Federal de Pernambuco, Recife, 2013.

SOUSA, M. L. Violência contra a escola: repercussões curriculares - o olhar do Conselho de Escola numa escola municipal de Santo André. 2015. 148 f. Dissertação (Mestrado em Educação) - Universidade Católica de São Paulo, São Paulo, 2015.

VERGNA, A. C. G. Indisciplina e violência na escola: concepções e discursos de educadores. 2016. 119 f. Dissertação (Mestrado em Educação) - Universidade Federal de São Carlos, São Carlos, 2016.

ZECHI, J. A. M. Educação em valores: solução para a violência na escola? 2014. 278 f. Tese (Doutorado em Educação) - Universidade Estadual Paulista, Presidente Prudente, 2014.

\section{Como referenciar este artigo}

PASSOS, S. M. S.; SANTOS, J. M. C. T.; MEDEIROS, E. A. M. Violência na Escola Pública: o que apontam teses e dissertações (2012-2019)? Revista on line de Política e Gestão Educacional, Araraquara, v. 25, n. 3, p. 2843-2860, set./dez. 2021. e-ISSN:15199029. DOI: https://doi.org/10.22633/rpge.v25i3.15343

Submetido em: $11 / 08 / 2021$

Revisões requeridas em: 17/09/2021

Aprovado em: 16/10/2021

Publicado em: 08/12/2021 